\title{
Fondos de Inversión: Un Glosario para Principiantes ${ }^{1}$
}

\author{
Jorge Ruiz-Menjivar, Nelly Nelson, y Jarrett Tsai
}

\section{Introducción}

El mejor momento para comenzar a invertir o ahorrar es ayer, ya sea para la jubilación, para enviar a su hijo o hija a la Universidad o para el pago inicial de una casa. Para poder tomar una decisión acertada sobre que vehículos financieros escoger para una cartera de inversiones o plan, es primero fundamental conocer las opciones disponibles en el mercado y entender los mecanismos y principios detrás de cada uno de estos vehículos de inversión. Hay libros enteros escritos sobre estos temas, pero con el propósito de este artículo es proporcionar un glosario breve, pero completo de los fondos principales de inversión financiera.

\section{Los 3 Sabores Principales de Fondos de Inversión y Ahorro}

Por simplicidad, dividimos en tres tipos principales los diferentes fondos de inversión financieros: (a) acciones, (b) bonos, y (c) dinero en efectivo y equivalentes de efectivo. A continuación describimos cada una de estas opciones.

\section{Acciones}

Sin lugar a duda, estos fondos son los comentados en los medios impresos y digitales. Hay canales de televisión que cubren el movimiento de estos fondos de inversión las 24/7, y espacios informativos que en noticieros que abordar el desempeño de la bolsa de valores cada día. Las acciones se pueden clasificarse en las siguientes categorías principales: acciones comunes y acciones preferentes. Dentro de estas categorías, hay diferentes estructuras de fondos que pueden dividirse en las siguientes:

- Acciones individuales. Una acción individual es simplemente una titularidad parcial de una empresa. Una manera fácil de entender este concepto es pensar en la empresa, digamos Apple o General Motors, por ejemplo, como una pizza enorme y cada accionista como propietario de una pequeña rebanada de esa pizza.

- Fondos mutuos de inversión. Un fondo mutuo de inversión es una cartera de valores que se compone típicamente de las múltiples acciones de varias empresas e industrias, que son activamente manejadas (vistas y escogidas por un gerente profesional, que las compra y vende típicamente sobre una base diaria). Estos fondos de inversión son administrados por agencias de corredores que cobran un porcentaje basado en honorarios, alrededor del $0.75 \%$ generalmente. La ventaja de invertir en un fondo mutuo es que el inversionista puede recibir el beneficio de diversificar su cartera de acciones sin necesidad de dinero suficiente para comprar cada acción por el fondo de propiedad individual. El refrán de "no poner todos los huevos en una cesta" describe con precisión la ventaja de invertir en fondos mutuos. Diversificación ayuda a reducir el riesgo de la inversión. La forma más

1. Este documento, FCS3352-Span, es uno de una serie de publicaciones del Departamento de Familia, Juventud y Ciencias de la Comunidad, Servicio de Extensión Cooperativa de la Florida, Instituto de Alimentos y Ciencias Agrícolas, Universidad de la Florida (UF/IFAS Extension). Fecha de primera publicación: diciembre 2020. Visite nuestro sitio web EDIS en https://edis.ifas.ufl.edu. The English version of this document is Major Asset Classes: A Brief Glossary (FCS3352).

2. Jorge Ruiz-Menjivar, assistant professor, Department of Family, Youth and Community Sciences; Nelly Nelson, Extension agent I, M.B.A., family and consumer sciences, UF/IFAS Extension Manatee County; and Jarrett Tsai, undergraduate student, Finance Department, UF Warrington College of Business; UF/IFAS Extension, Gainesville, FL 32611.

The Institute of Food and Agricultural Sciences (IFAS) is an Equal Opportunity Institution authorized to provide research, educational information and other services

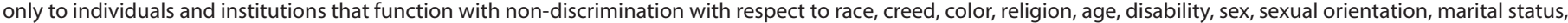

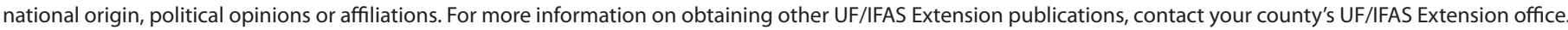
U.S. Department of Agriculture, UF/IFAS Extension Service, University of Florida, IFAS, Florida A \& M University Cooperative Extension Program, and Boards of County Commissioners Cooperating. Nick T. Place, dean for UF/IFAS Extension. 
fácil de pensar en esto es si usted tiene 10 acciones en una sola compañía y esta rinde mal en operaciones, entonces su retorno a la inversión se vera afectada negativamente. Ahora si usted tiene 10 acciones, 3 rinden pesimamente, pero 7 tienen éxito, en promedio usted tendrá un mejor retorno a su inversión.

- ETF (Fondo negociado de intercambio). Son un conjunto de acciones coladas por una empresa para seguir un amplio índice bursátil. El ETF más común es la que sigue el índice Standard y Pobre 500 (Standard \& Poor 500 en inglés, o también abreviado como S\&P 500). Este índice bursátil sigue el movimiento de la 500 empresas más grandes en los Estados Unidos. El S\&P 500 se utiliza a menudo como un aproximado o un indicador para el bienestar general de la economía. El beneficio de invertir en un ETF es que usted puede seguir los movimientos de los mercados y los beneficios de diversificación.

- Derivados. Un derivado simplemente significa un vehículo de inversión (y su valor respectivo) derivado de o en relación con otros bienes, en este caso, se basa en el precio de otro las activo. El derivado más común es un contrato de opciones. Este es un contrato que da derecho al propietario a comprar o vender una acción a cierto precio y tiempo. Los principales usos de estos contratos son como un seguro o para especular en el mercado. Hay estrategias financieras que el inversionista promedio puede tomar, incluso utilizando derivados, pero es aconsejable para un inversionista tener una fuerte comprensión de las mecánicas de este vehículo de inversión.

- Fondo de cobertura. Estos fondos (también conocidos como Instrumento de Inversión Alternativa) emplean estrategias complejas y a menudo altamente arriesgadas y sólo están disponibles para inversores acreditados. Uno de los requisitos para ser un inversionista acreditado es un poder adquisitivo superior a 1 millón de dólares.

\section{Bonos}

- Bonos del gobierno. Bonos son fondos de inversion basada en el sistema deuda, en donde le inversionista sirve de prestamista al gobierno a cambio de una tasa de interes acordada. Típicamente, los bonos pagan "cupones" que simplemente significa que cada seis meses recibirá un pago de interés pequeño en el dinero que ha prestado hasta que el bono madura (es decir, la deuda se ha pagado en su totalidad). La mayor preocupación con los bonos es que el prestatario, en este caso el gobierno, podría faltar al pago. Afortunadamente, en el caso del gobierno de Estados Unidos, este evento de incumplimiento de pago se percibe como poco probable, pues en teoría, el gobierno Federal podría continuar imprimiendo dinero para pagar cualquier deuda que sea necesario. Debido a que el riesgo de incumplimiento de pago es bajo, el retorno a la inversión en bonos es usualmente mas baja que de las acciones.

- Bonos corporativos. Bonos corporativos son bonos emitidos por corporaciones en lugar del gobierno. Son percibidos como más riesgosos porque una empresa tiene un riesgo mucho mayor de ir a quiebra, y consecuentemente de cesación de pagos de sus deudas que el gobierno de los Estados Unidos.

- Bonos municipales. Estos vehículos de inversión son similares a bonos emitidos por las corporaciones o el gobierno con la diferencia que los bonos municipales son emitidos por las municipalidades-es decir gobiernos locales y estatales. El dinero usado para pagar estos, es generado por los ingresos de los impuestos de esa municipalidad especifica.

- Fondos de inversión mobiliaria. Similares a los fondos de inversión, pues estan compuestos de acciones, los fondos de inversion mobiliaria son también fondos mutuos compuestos de múltiples bonos. Como se mencionó anteriormente, los fondos mutuos ofrecen una oportunidad de invertir en un medio que se beneficia de la diversificación sin necesidad de incremetar la inversion para comprar cada bono dentro del fondo.

\section{Efectivo y Equivalentes de Efectivo}

- Cuenta de ahorros. Estos fondos no son optimos para inversiones, sino para ahorrors en general. Estas cuentas son para gastos diarios y usualmente pagan una tasa interés insignificante, normalmente menos de $0.05 \%$.

- Certificados de Depósito (CD). La función de CD es similar a los bonos. El inversionista hace un depósito en un banco, generalmente de 1.000 dólares, para un período de tiempo determinado, y el banco, en retorno, paga más intereses sobre el monto depositado. Al final del tiempo especificado, el banco paga al inversionista el monto depositado mas los intereses acordados por el periodo de tiempo. CD están asegurados por el gobierno y son calificados como inversiones de bajo riesgo-por consiguiente, el tasa de retorno de inversión es bajo comparado con el retorno en acciones.

- Cuentas del mercado monetario. Estas cuentas se asemejan al mecanismo de las cuentas de ahorro y corrientes, pero ganan un mayor porcentaje de interés que las antes dichas. En términos simples, una institución financiera (por ejemplo, un banco) invierte su dinero en su nombre en activos de bajo riesgo. Estos tipos 
de cuentas también están asegurados por el gobierno. Cuentas del mercado monetario requieren ligeramente requisitos mínimos del saldo de ahorro tradicional o comprobación de cuentas bancarias y limitan la capacidad de emitir cheques.

\section{Referencia}

Bodie, Z., Kane, J. A., \& Marcus, A. (2012). Fundamentos de inversiones 9na edición. McGraw-Hill. 